\title{
Efeitos do incremento da fibra em detergente neutro na ração de suínos sobre a histologia de segmentos do trato intestinal
}

Jacinta Diva Ferrugem GOMES ${ }^{1}$

Francisco Javier Hernandez BLAZQUEZ ${ }^{2}$

Romualdo Shigueo

FUKUSHIMA ${ }^{3}$

Carlos Eduardo UTIYAMA ${ }^{4}$

Liliana Lotufo OETTING ${ }^{4}$

Gustavo Júlio Melo

Monteiro de LIMA $^{5}$

Correspondência para: JACINTA DIVA FERRUGEM GOMES

Departamento de Zootecnia

Faculdade de Zootecnia e Engenharia de Alimentos

Universidade de São Paulo

Av. Duque de Caxias Norte, 225

$13635-900$ - Pirassununga - SP

jacintaf@usp.br

Recebido para publicação: 21/07/2005 Aprovado para publicação: 23/08/2005

1 - Departamento de Zootecnia da Faculdade de Zootecnia e Engenharia de Alimentos da Universidade de São Paulo, Pirassununga - SP

2 - Departamento de Cirurgia da Faculdade de Medicina Veterinária e Zootecnia da Universidade de São, São Paulo - SP

3 - Departamento de Nutrição e Produção Animal da Faculdade de Medicina Veterinária e Zootecnia da Universidade de São Paulo, São Paulo - SP

4 - Escola Superior de Agricultura Luiz de Queiroz da Universidade de São Paulo, Piracicaba - SP

5 - Centro Nacional de Pesquisa em Suínos e Aves EMBRAPA - SC

\section{Resumo}

Objetivou-se registrar os efeitos da inclusão de 0 ou $8 \%$ de fibra em detergente neutro na ração de suínos, sobre a histologia intestinal de suínos nas fases de creche e de crescimento-terminação. Foram utilizados suínos mestiços alimentados à vontade com rações isoprotéicas e isoenergéticas, em experimento inteiramente casualizado. Ao final de cada período, os animais foram abatidos, eviscerados e os cortes histológicos realizados. A ração fibrosa promoveu, na creche, significativo aumento da proporção volumétrica glandular na mucosa cecal; redução da proporção volumétrica ocupada pelas células caliciformes no epitélio do jejuno; aumento das áreas de células caliciformes produtoras de muco, presentes no epitélio glandular do jejuno, ceco e colo; além de aumento na intensidade do muco presente nas células caliciformes do duodeno e colo. Ao final da fase de terminação, os suínos alimentados com as dietas fibrosas, apresentaram aumento da proporção volumétrica glandular do epitélio do ceco, mas ligeira redução da área das células caliciformes produtoras de muco, no epitélio do colo. Estes dados sugerem uma adaptação, possivelmente um mecanismo de proteção, do epitélio à ação abrasiva exercida pelo oferecimento contínuo de fibra dietética na dieta de suínos, particularmente na fase creche.

\section{Introdução}

As rações formuladas para suínos, conforme diferentes finalidades, são primordialmente constituídas de grãos. Isto representa uma preocupante competição com a alimentação humana ${ }^{1,2}$. A possibilidade de se utilizar forragens e outros volumosos contendo elevados teores de fibra em detergente neutro (FDN), como fonte de energia na produção de suínos ${ }^{3}$, pode amenizar esta situação, particularmente naquelas regiões onde é problemática a produção de grãos. Outra grande vantagem auferida por uma ração mais fibrosa, é que esta, tendo densidade energética menor, possibilita a sensação de saciedade naqueles animais cujo acúmulo excessivo de gordura é indesejável, tais como os destinados ao abate nas fases de terminação, pósterminação (185 dias e $135 \mathrm{~kg})^{4,5,6}$, e os de puberdade, além de minimizar o estresse advindo do confinamento e da restrição alimentar de fêmeas reprodutoras $7,8,9$.

Dada a limitada capacidade do trato digestivo desta espécie animal em processar material fibroso, são recomendados estudos sobre o potencial destes alimentos na 
produção suína, particularmente as interações entre os efeitos fisiológicos e associativos sobre a morfo-histologia dos órgãos intestinais, causados pelo conteúdo fibroso variável, existente entre os diversos ingredientes e fontes alimentares ${ }^{1}$. O desempenho animal é extremamente dependente $\mathrm{da}$ integridade anatômica intestinal. Esta é afetada pela fonte alimentar utilizada, especialmente pela origem e a quantidade de fibra da ração ${ }^{10,11}$. A integridade anatômica está diretamente relacionada com a manutenção do adequado número de células, bem como de sua capacidade funcional, determinada pela situação de equilíbrio entre a perda e a renovação celular do epitélio intestinal ${ }^{12}$.

Considerável parte da literatura registra trabalhos onde são empregados teores relativamente altos de fibra na ração de suínos. Entretanto, esta prática pode anular os possíveis efeitos benéficos advindos da utilização da fibra; por exemplo, foi detectada perda do epitélio em diversos animais alimentados com dietas fibrosas ${ }^{13}$. Considerando-se que os suínos são animais de ceco simples, com moderada capacidade de aproveitamento da fibra nas porções inferiores do trato digestivo, traduzida pela produção de ácidos graxos de cadeia curta ${ }^{14}$, é que realizamos a presente pesquisa, para avaliar os efeitos de níveis moderados de adição de FDN na ração, de 0 ou $8 \%$, sobre a histologia de segmentos do trato intestinal de suínos.

\section{Materiais e Métodos}

A pesquisa foi conduzida no Setor de Suinocultura do Campus de Pirassununga, Universidade de São Paulo, Pirassununga, SP.

Para o experimento da fase de creche, foram utilizados 26 leitões, fêmeas e machos castrados, mestiços (Large White? Landrace) com idade e peso inicial de 42 dias e $11,3 \mathrm{~kg}$ e idade e peso final de 73 dias e $28,1 \mathrm{~kg}$, respectivamente. Os animais foram alojados em baias coletivas $\left(2,13 \mathrm{~m}^{2}\right.$ /animal), equipadas com bebedouro tipo chupeta e comedouro semi-automático. Água e ração foram fornecidos ad libitum, durante todo o período experimental (30 dias). A desmama foi realizada quando os leitões chegaram aos 21dias de idade e no sistema de desmame total.

Para o experimento envolvendo as fases de crescimento e terminação, foram utilizados 24 suínos mestiços (Large White? Landrace), fêmeas e machos castrados, com idade e peso inicial de 74 dias e $25,0 \mathrm{~kg}$ e idade e peso final de 146 dias e $88,3 \mathrm{~kg}$, respectivamente. Os animais foram alojados em gaiolas individuais (medindo 1,8 $\mathrm{m}^{2}$ ), equipadas com bebedouro tipo chupeta $\mathrm{e}$ comedouro semi-automático. Água e ração foram fornecidas ad libitum, durante todo o período experimental (72 dias). Estas gaiolas ficaram localizadas em um galpão aberto com área de $140 \mathrm{~m}^{2}$, coberto com telhas de barro e pé direito de 3,5 metros.

Os suínos receberam, durante todo o período experimental, rações isoenergéticas e isoprotéicas (Tabela 1), formuladas de acordo com as tabelas de exigências nutricionais constantes no $\mathrm{NRC}^{15}$. A fonte de FDN foi proveniente do feno de Tifton (Cynodon dactylon), o qual foi finamente moído e adicionado à ração farelada dos animais experimentais, o qual receberam $8 \%$ de FDN. O grupo controle não foi suplementado. Os teores de FDN no feno de Tifton foram determinados seguindo o procedimento laboratorial descrito por Goering e Van Soest ${ }^{16}$. As demais análises laboratoriais seguiram as rotinas descritas em $\mathrm{AOAC}^{17}$.

Os suínos foram abatidos de forma convencional, sendo que antes do abate propriamente dito, os suínos passaram por jejum hídrico e alimentar de 16 horas. A cavidade abdominal de cada suíno foi aberta por incisão longitudinal, retirando-se e pesando-se os órgãos digestivos. Em seguida, os mesmos foram abertos longitudinalmente. Anteriormente à lavagem destes órgãos, segmentos de cerca de $1 \mathrm{~cm}$ de lado, foram acondicionados em líquido fixador de Bouin por 24 horas, e em fixador 
McDowell, segundo a rotina usual para inclusão em parafina e em historresina, respectivamente. Os cortes de 2 e $4 \mu \mathrm{m}$ foram colhidos em lâminas de vidro e corados pelo método da hematoxilina e eosina para estudo histológico.

Embora a medida da área citoplasmática possa ser muito útil para estimar a atividade metabólica de células isoladas, para tecidos, a medida da proporção de volume pelo método de contagem de pontos pode oferecer melhores informações sobre a contribuição relativa da atividade funcional. Assim, a proporção volumétrica de células secretoras ou das glândulas estima a quantidade proporcional de tecido secretor ativo no epitélio ou na mucosa ${ }^{18}$. A proporção volumétrica ou fração de volume $\left(V_{v}\right)$ das estruturas avaliadas foi obtida utilizando-se um microscópio ótico Zeiss com ocular de retículo com 360 pontos. Após acoplar a ocular ao microscópio, utilizou-se uma objetiva de imersão $(100 \times)$. A Vv das células caliciformes foi calculada obtendo-se a fração de pontos que coincidia com estas células em relação ao total de pontos sobre o epitélio intestinal glandular. Da mesma maneira, a Vv das glândulas intestinais em relação à mucosa intestinal foi obtida pela fração dos pontos sobre as glândulas em relação ao total de pontos sobre a mucosa. Estas duas medidas de $\mathrm{Vv}$ foram expressas em porcentagem ${ }^{18}$.

A quantidade de muco no citoplasma da célula caliciforme foi estimada de duas maneiras: pelo cálculo da área ocupada pelo muco no citoplasma e pela medida da intensidade da coloração do muco citoplasmático ao ácido periódico-reativo de Schiff (PAS) ${ }^{19}$. Com este fim foram realizados cortes histológicos de 1 ?m e observados com uma objetiva de imersão de 100×; foram digitalizadas imagens em tons de cinza das células coradas pelo PAS sem coloração de fundo. A quantidade relativa de muco neutro em cada célula foi estimada pela medida do nível médio de cinza da área alvo. Para esta finalidade foi usado o sistema de análise de imagens Kontron
Zeiss KS 4.0. Este sistema mede valores da intensidade de coloração em unidades arbitrárias, que variam de zero (cor negra) a 255 (cor branca) com valores intermediários equivalentes às tonalidades de cinza. A intensidade da coloração é proporcional à concentração do muco intracelular, estimando-se que quanto mais muco o citoplasma contém, mais escura é a coloração. Para se ter uma relação direta entre a produção de muco, a intensidade de coloração e o número apresentado, subtraímos de 255 todos os valores obtidos. A área do citoplasma das células caliciformes foi medida pelo mesmo sistema. As análises histológicas foram realizadas no Laboratório de Citologia, Histologia e Embriologia, do Departamento de Ciências Básicas da Faculdade de Zootecnia e Engenharia de Alimentos da Universidade de São Paulo.

O delineamento experimental empregado foi o de blocos inteiramente casualizados, com dois tratamentos $(0$ ou $8 \%$ de FDN) e 13 repetições por tratamento para o experimento da creche e 12 repetições por tratamento para o experimento do crescimento-terminação, sendo as variabilidades relativas a peso e idade. A análise de variância foi realizada através do procedimento "General Linear Model" do $\mathrm{SAS}^{20}$. As médias dos parâmetros estudados foram comparadas pelo teste de Tukey $(P=0,05 ; P=0,01)$.

\section{Resultados e Discussão}

As fontes fibrosas que não são digeridas pelas enzimas do intestino delgado, quando presentes no trato intestinal, podem afetar diretamente as características físicas do conteúdo intestinal, e conseqüentemente a própria morfo-histologia dos órgãos envolvidos no processo digestivo ${ }^{21}$.

O estudo dos cortes histológicos revelou alterações epiteliais no intestino de suínos ao final da fase de creche (Tabela 2, 3, 4 e 5), mas não nos de terminação (Tabela 6 e 7 ).

A avaliação histológica do epitélio 
intestinal dos leitões alimentados continuamente com ração contendo fibra dietética parcialmente substituindo o concentrado energético, durante a fase final de creche, revelou aumento significativo $(P=0,001)$ de $10,6 \%$ do volume ocupado pelas glândulas na camada mucosa do ceco (Tabela 2); redução significativa $(P=0,001)$ de $15 \%$ do volume ocupado pelas células caliciformes do epitélio do jejuno (Tabela 3); aumento significativo da área das células caliciformes do epitélio (Tabela 4) do jejuno (72,8\% - $P=0,01)$, ceco $(22,6 \%-P=0,001$; Figura 1 e 2$)$ e colo $(45,5 \%$ - $P=0,05)$, bem como aumento da produção de muco pelas células caliciformes (Tabela 5) do duodeno $(3,3 \%$ - $P=0,01)$ e do colo $(15,3 \%$ $P=0,001)$. Assim, no intestino delgado a resposta ao incremento de fibra em substituição ao milho na ração sobre a produção de muco foi menor que a verificada no intestino grosso. No duodeno, houve apenas um ligeiro aumento da produção de muco e no jejuno, apesar das células mucosas terem aumentado de tamanho, o volume que ocupavam no epitélio se reduziu. Contudo, no ceco e no colo, houve aumento do volume ocupado pelas glândulas, aumento da área das células caliciformes e aumento da produção de muco. Tais respostas podem ser fortes indicativos de adaptação do epitélio intestinal do suíno jovem, em função do contínuo período de oferecimento de ração contendo fibra dietética, como sugerido por Varel e Pond $^{22}$, uma vez que esta é uma fase na qual os leitões não apresentam seus órgãos digestivos totalmente desenvolvidos, particularmente o intestino grosso. As Figuras 1 e 2 mostram as microfotografias da mucosa do ceco de animais recebendo $0 \%$ e $8 \%$ de FDN adicionado às dietas, respectivamente. Pode-se observar claramente os efeitos que a adição de fibra na ração provoca no epitélio.

Dietas fibrosas atuam sobre a mucosa intestinal, estimulando a produção e liberação de muco pelas glândulas intestinais. Esta ação seria resultante da proliferação celular do epitélio intestinal causada pelo aumento da concentração dos ácidos graxos voláteis no intestino grosso, em decorrência da fermentação da fibra dietética da ração ${ }^{23,24}$.

Por outro lado, o aumento da produção de muco, pode ser também uma tentativa de proteção das células do intestino grosso aos fatores físicos inerentes à fibra alimentar, como os de natureza volumosa e abrasiva, como sugerido por Sakata ${ }^{25}$. É de se esperar que fontes fibrosas pouco fermentáveis tenham mais características abrasivas, e neste caso, a maior produção de muco pode ser encarada como resposta saudável do epitélio intestinal ${ }^{26}$. Contrariamente, Moore et al. ${ }^{13}$ não observaram alterações significativas nas células intestinais de suínos em fase de creche alimentados com níveis mais elevados de FDN (14, 16 e 17\%), exceto que em alguns animais foram encontrados indícios significativos de prejuízo no epitélio intestinal, apontando que certos indivíduos poderiam, ser ou estar mais susceptíveis à ação abrasiva, em decorrência da presença de fibra na $\operatorname{dieta}^{27}$. Cera e Tucci ${ }^{11}$ alertaram que a redução da superfície epitelial dos intestinos, promovida pela diminuição de suas vilosidades, representa um dos principais motivos da redução da capacidade absortiva intestinal, sendo a fase de creche, a mais crítica para o surgimento de distúrbios intestinais, uma vez que os leitões ainda não apresentam seu trato gastrointestinal totalmente desenvolvido. Aumento na perda e na taxa de produção de células intestinais compromete todo o processo digestivo de leitões jovens, em especial quando a dieta apresenta elevados níveis de ingredientes fibrosos ${ }^{28}$.

Suínos alimentados continuamente com dieta contendo incremento de $8 \%$ de FDN, em substituição ao milho, durante toda a fase de crescimento-terminação, apresentaram ao final da fase de terminação tendências de alterações nos parâmetros histológicos relacionados aos percentuais da área glandular do ceco (Tabela 6) e da área ocupada pelas células caliciformes do colo 
Tabela 1 - Composição percentual das rações experimentais oferecidas aos suínos durante as fases de creche, crescimento e terminação.

\begin{tabular}{|c|c|c|c|c|c|c|c|c|}
\hline \multirow{4}{*}{ Ingredientes } & \multicolumn{8}{|c|}{ Fases } \\
\hline & \multicolumn{3}{|c|}{ Creche } & & \multicolumn{2}{|c|}{ Crescimento } & \multicolumn{2}{|c|}{ Terminação } \\
\hline & \multicolumn{3}{|c|}{ FDN, \% } & & \multicolumn{2}{|c|}{ FDN, \% } & \multicolumn{2}{|c|}{ FDN, \% } \\
\hline & 0 & & 8 & & 0 & 8 & 0 & 8 \\
\hline Milho & 67,53 & & 57,00 & & 80,83 & 65,93 & 86,26 & 72,14 \\
\hline Farelo de soja & 24,86 & & 24,95 & & 16,00 & 17,44 & 10,70 & 11,89 \\
\hline Feno moído & - & & 10,00 & & - & 10,00 & - & 10,00 \\
\hline Açúcar & 3,90 & & 3,00 & & - & - & - & - \\
\hline Gordura & 0,40 & & 1,80 & & - & - & - & - \\
\hline Óleo & - & & - & & - & 3,71 & - & 3,45 \\
\hline Fosfato bicálcico & 2,40 & & 2,31 & & 1,82 & 1,80 & 1,38 & 1,35 \\
\hline $\begin{array}{l}\text { Calcário } \\
\text { calcítico }\end{array}$ & - & & - & & 0,21 & 0,15 & 0,27 & 0,22 \\
\hline Caulim & - & & - & & 0,16 & - & 0,44 & - \\
\hline Sal & 0,30 & & 0,30 & & 0,30 & 0,30 & 0,30 & 0,30 \\
\hline $\begin{array}{l}\text { Suplemento } \\
\text { micromineral }\end{array}$ & $0,10^{\mathrm{a}}$ & & $0,10^{\mathrm{a}}$ & & $0,10^{\mathrm{C}}$ & $0,10^{\mathrm{C}}$ & $0,10^{\mathrm{C}}$ & $0,10^{\mathrm{C}}$ \\
\hline $\begin{array}{l}\text { Suplemento } \\
\text { vitamínico }\end{array}$ & $0,40^{\mathrm{b}}$ & & $0,40^{b}$ & & $0,40^{\mathrm{d}}$ & $0,40^{\mathrm{d}}$ & $0,40^{d}$ & $0,40^{d}$ \\
\hline L-Lisina & 0,110 & & 0,140 & & 0,180 & 0,170 & 0,150 & 0,150 \\
\hline Total & & & & & & 100,00 & & \\
\hline \multicolumn{9}{|l|}{ Valores obtidos } \\
\hline $\begin{array}{c}\text { E.D., kcal/kg } \\
\text { ração }\end{array}$ & 3.265 & $\begin{array}{c}3.26 \\
5\end{array}$ & & $\begin{array}{c}3.27 \\
4\end{array}$ & $\begin{array}{l}3.2 \\
67\end{array}$ & $\begin{array}{c}3.29 \\
7\end{array}$ & \multicolumn{2}{|l|}{3.276} \\
\hline P.B., \% & 17,50 & $\begin{array}{c}17,3 \\
2\end{array}$ & & $\begin{array}{c}14,3 \\
0\end{array}$ & $\begin{array}{l}14 \\
35\end{array}$ & $\begin{array}{c}12,5 \\
0\end{array}$ & \multicolumn{2}{|l|}{12,64} \\
\hline $\mathrm{Ca}, \%$ & 0,77 & 0,71 & & 0,53 & $\begin{array}{c}0,5 \\
5\end{array}$ & 0,62 & \multicolumn{2}{|l|}{0,62} \\
\hline$P, \%$ & 0,53 & 0,50 & & 0,53 & $\begin{array}{c}0,5 \\
5\end{array}$ & 0,50 & \multicolumn{2}{|l|}{0,49} \\
\hline $\begin{array}{l}\text { FDN oferecido } \\
\text { pelo feno, } \%\end{array}$ & - & 8,00 & & - & $\begin{array}{c}8,0 \\
0\end{array}$ & - & 8,00 & \\
\hline
\end{tabular}

aSuprindo as seguintes quantidades por kg de ração: $\mathrm{Fe} 45 \mathrm{mg}$; Cu 7,5 mg; Mn 7,5 mg: Zn 65 g; 142 mg; Co $10 \mathrm{mg}$. bSuprindo as seguintes quantidades por kg de ração: vit. A 6500 Ul; vit. D 1500 Ul; vit. E 15 Ul; vit. K 2,8 mg; vit. B 1,5 mg; vit. B 4 mg; vit. B 1,5 mg; vit. B 18 mcg; ác. nicotínico $20 \mathrm{mg}$ a 7,5 mg; Zn 65 g; 142 mg; Co 10 mg. 'S Suprindo as seguintes quantidades por kg de ração: vit. A 6500 Ul; vit. D 1500 Ul; vit. E 15 Ul; vit. K 2,8 mg; vit. $B_{1} 1,5$ mg; vit. $B_{2} 4$ mg; vit. $B_{6} 1,5$ gg; vit. $B_{12} 18$ mcg; ác. nicotínico 20 mg; ác. fólico 0,55 mg; ác. pantotênico 15 mg; biotina $12 \mathrm{mg}$.

(Tabela 7), embora a diferença não seja significativa. Aparentemente, uma vez superada a fase de creche, os animais foram capazes de tolerar a presença de quantidade moderada de fibra na ração. Observação lógica, uma vez que são animais já mais desenvolvidos.

Por outro lado, Jin et al. ${ }^{11}$ detectaram aumento na taxa de renovação das células epiteliais do colo, responsáveis pelo aumento da produção de muco no intestino de suínos, na fase de crescimento, recebendo níveis elevados de FDN (17\%) na ração. Suínos na fase de puberdade alimentados com dietas contendo de 13 a 20\% de FDN apresentaram aumento significativo da área ocupada pelas células caliciformes no epitélio do ceco e intensa reação histoquímica do PAS, confirmando que rações com elevados teores de fibra promoveram aumento na 
Tabela 2 - Valores médios da proporção de volume (\%) ocupada pelas glândulas na mucosa dos intestinos delgado e grosso, de leitões em fase final de creche, alimentados com rações contendo incremento de fibra em detergente neutro (FDN)

\begin{tabular}{|c|c|c|c|c|c|c|}
\hline \multirow{2}{*}{ Órgãos } & \multicolumn{2}{|c|}{$\begin{array}{c}\text { Incremento de FDN na } \\
\text { ração, \% }\end{array}$} & \multirow{2}{*}{ Média } & \multicolumn{3}{|c|}{ Análise de variância } \\
\hline & 0 & 8 & & $\mathrm{EPM}^{1}$ & $\mathrm{CV}^{2}, \%$ & $\mathrm{P}=\mathrm{F}$ \\
\hline Duodeno & $38,18^{\mathrm{a}}$ & $38,36^{\mathrm{a}}$ & 38,27 & 6,5726 & 17,17 & 0,8223 \\
\hline Jejuno/Íleo & $39,13^{\mathrm{a}}$ & $39,74^{\mathrm{a}}$ & 39,45 & 8,0946 & 20,52 & 0,5478 \\
\hline $\mathrm{Ceco}^{* *}$ & $39,50^{\mathrm{a}}$ & $43,68^{b}$ & 41,59 & 8,0912 & 19,46 & 0,0001 \\
\hline Colo & $41,98^{\mathrm{a}}$ & $43,76^{a}$ & 42,87 & 8,7950 & 20,52 & 0,1041 \\
\hline
\end{tabular}

'Erro padrão da média, ${ }^{2}$ Coeficiente de variação. Médias na mesma linha com letras diferentes divergem significativamente $(* * p<0,01)$ pelo Teste deTukey. $\mathrm{N}=13$ animais/tratamento.

Tabela 3 - Valores médios da proporção de volume $(\%)$ ocupado pelas células caliciformes produtoras de muco, observados no epitélio glandular dos intestinos delgado e grosso, de leitões em fase final de creche, alimentados com rações contendo incremento de fibra em detergente neutro (FDN)

\begin{tabular}{|c|c|c|c|c|c|c|}
\hline \multirow{2}{*}{ Órgãos } & \multicolumn{2}{|c|}{$\begin{array}{l}\text { Incremento de FDN na } \\
\text { ração, \% }\end{array}$} & \multirow{2}{*}{ Média } & \multicolumn{3}{|c|}{ Análise de variância } \\
\hline & 0 & 8 & & $\mathrm{EPM}^{1}$ & $\mathrm{CV}^{2}, \%$ & $\mathrm{P}=\mathrm{F}$ \\
\hline Duodeno & $19,79^{\mathrm{a}}$ & $18,70^{\mathrm{a}}$ & 19,27 & 8,9459 & 46,44 & 0,3395 \\
\hline Jejuno/Íleo** & $20,52^{\mathrm{a}}$ & $17,45^{\mathrm{b}}$ & 18,97 & 7,3224 & 38,61 & 0,0009 \\
\hline Ceco & $17,80^{\mathrm{a}}$ & $18,87^{a}$ & 18,36 & 7,8921 & 42,99 & 0,2851 \\
\hline Colo & $19,67^{\mathrm{a}}$ & $20,56^{a}$ & 20,12 & 8,6335 & 42,91 & 0,4099 \\
\hline
\end{tabular}

${ }^{1}$ Erro padrão da média, ${ }^{2}$ Coeficiente de variação. Médias na mesma linha com letras diferentes divergem significativamente $(* *$ d" 0,01$)$ pelo Teste de Tukey. $\mathrm{N}=13$ animais/tratamento

Tabela 4-Valores médios daárea (mm) das células caliciformes produtoras de muco, presentes no epitélio glandular dos intestinos delgado e grosso de leitões em fase final de creche, alimentados com rações contendo incremento de fibra em detergente neutro (FDN)

\begin{tabular}{|c|c|c|c|c|c|c|}
\hline \multirow{2}{*}{ Órgãos } & \multicolumn{2}{|c|}{$\begin{array}{c}\text { Incremento de FDN } \\
\text { na ração, \% }\end{array}$} & \multirow{2}{*}{ Média } & \multicolumn{3}{|c|}{ Análise de variância } \\
\hline & 0 & 8 & & $\mathrm{EPM}^{1}$ & $\mathrm{CV}^{2}, \%$ & $\mathrm{P}=\mathrm{F}$ \\
\hline Duodeno & $65,69^{a}$ & $63,04^{\mathrm{a}}$ & 64,43 & 27,5976 & 42,83 & 0,0701 \\
\hline Jejuno/Íleo* & $56,20^{\mathrm{a}}$ & $97,13^{b}$ & 76,67 & 28,9765 & 43,63 & 0,0042 \\
\hline $\mathrm{Ceco}^{* *}$ & $57,95^{\mathrm{a}}$ & $71,05^{b}$ & 63,72 & 29,9854 & 47,06 & 0,0001 \\
\hline Colo* & $59,18^{\mathrm{a}}$ & $86,11^{b}$ & 73,38 & 22,4844 & 30,19 & 0,0335 \\
\hline
\end{tabular}

'Erro padrão da média, ${ }^{2}$ Coeficiente de variação. Médias na mesma linha com letras diferentes divergem significativamente $(* *$ pd" 0,$01 ; *$ pd" 0,05$)$ pelo Teste de Tukey. $\mathrm{N}=13$ animais/tratamento

produção de muco, possivelmente uma tentativa de proteger o epitélio contra a ação abrasiva da fibra?.

De qualquer maneira, estes dados sugerem adaptação orgânica dos animais ao componente fibra por mecanismos ainda desconhecidos ${ }^{21}$. Os seus respectivos significados biológicos ainda não estão completamente explicados, sugerindo-se desta maneira, maiores estudos sobre as mais diversas respostas do trato gastrintestinal às rações contendo diferentes fontes e concentrações de fibra dietética.

\section{Conclusões}

O oferecimento contínuo de dieta contendo incremento de moderado nível de 
Tabela 5 - Valores médios, em unidades arbitrárias, da intensidade de coloração ao PAS da produção de muco presente das glândulas caliciforme dos intestinos delgado e grosso de leitões em fase final de creche, alimentados com rações contendo incremento de fibra em detergente neutro (FDN)

\begin{tabular}{|c|c|c|c|c|c|c|}
\hline \multirow{2}{*}{ Órgãos } & \multicolumn{2}{|c|}{$\begin{array}{c}\text { Incremento de FDN } \\
\text { na ração, \% }\end{array}$} & \multirow{2}{*}{ Média } & \multicolumn{3}{|c|}{ Análise de variância } \\
\hline & 0 & 8 & & $\mathrm{EPM}^{1}$ & $\mathrm{CV}^{2}, \%$ & $\mathrm{P}=\mathrm{F}$ \\
\hline Duodeno** & $44,02^{\mathrm{a}}$ & $45,47^{b}$ & 44,71 & 9,5284 & 21,31 & 0,0043 \\
\hline Jejuno/Íleo & $42,66^{\mathrm{a}}$ & $41,83^{\mathrm{a}}$ & 42,20 & 9,9984 & 23,69 & 0,1153 \\
\hline Ceco & $39,87^{\mathrm{a}}$ & $39,48^{\mathrm{a}}$ & 39,70 & 12,4276 & 31,31 & 0,6173 \\
\hline Colo** & $38,63^{\mathrm{a}}$ & $44,53^{\mathrm{b}}$ & 41,74 & 11,10 & 26,60 & 0,0001 \\
\hline
\end{tabular}

'Erro padrão da média, ${ }^{2}$ Coeficiente de variação. Médias na mesma linha com letras diferentes divergem significativamente $(* *$ pd" 0,01$)$ pelo Teste de Tukey. $\mathrm{N}=13$ animais/tratamento

Tabela 6 - Valores médios da proporção de volume (\%) ocupada pelas glândulas intestinais na mucosa dos intestinos delgado e grosso de suínos em fase final de terminação alimentados com rações contendo incremento de fibra em detergente neutro (FDN)

\begin{tabular}{|c|c|c|c|c|c|c|}
\hline \multirow{2}{*}{ Órgãos } & \multicolumn{2}{|c|}{$\begin{array}{l}\text { Incremento de FDN na } \\
\text { ração, \% }\end{array}$} & \multirow{2}{*}{ Média } & \multicolumn{3}{|c|}{ Análise de Variância } \\
\hline & 0 & 8 & & $\mathrm{EPM}^{1}$ & $\mathrm{CV}^{2}, \%$ & $P=F$ \\
\hline Duodeno & 40,81 & 40,30 & 40,56 & 6,93 & 17,09 & 0,5726 \\
\hline Jejuno/Íleo & 40,60 & 41,71 & 41,18 & 7,70 & 18,71 & 0,2752 \\
\hline Ceco & 38,91 & 40,43 & 39,67 & 7,17 & 18,08 & 0,1024 \\
\hline Colo & 40,05 & 41,10 & 40,57 & 7,87 & 19,41 & 0,3038 \\
\hline
\end{tabular}

${ }^{1}$ Erro padrão da média, ${ }^{2}$ Coeficiente de variação. Não houve diferença significativa pelo teste de Tukey. $\mathrm{N}=12$ animais/tratamento

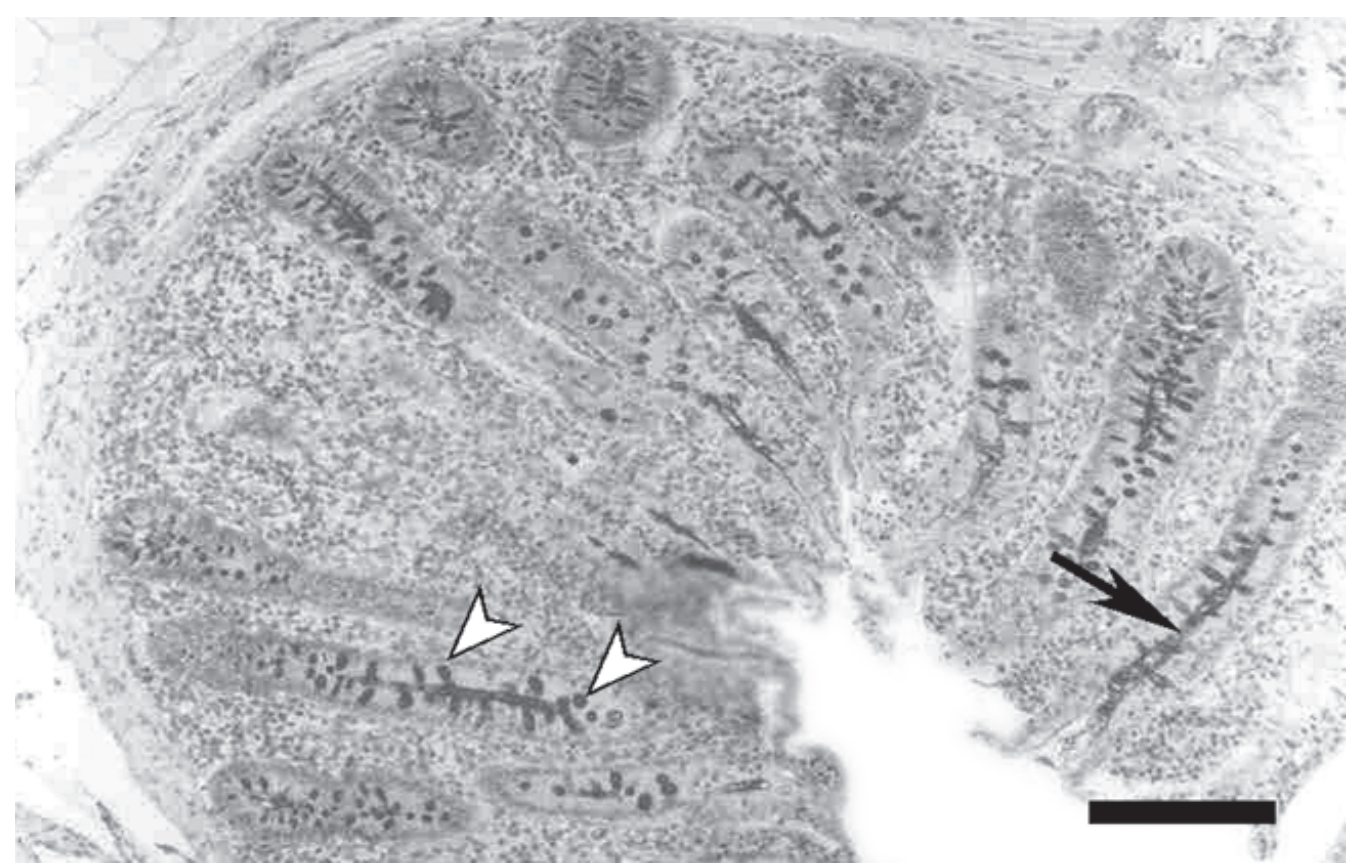

Figura 1 - Microfotografia da mucosa do ceco de um animal recebendo 0\% de FDN adicionado à dieta. As pontas de seta (em branco) indicam células caliciformes. A seta (em preto) indica uma glândula intestinal. Barra $=100$ um; Coloração Hematoxilina - PAS 
Tabela 7 - Valores médios da proporção de volume (\%) ocupada pelas células caliciformes, produtoras de muco, em relação ao epitélio glandular dos intestinos delgado e grosso de suínos em fase final de terminação, alimentados com rações contendo incremento de fibra em detergente neutro (FDN)

\begin{tabular}{|c|c|c|c|c|c|c|}
\hline \multirow{2}{*}{ Órgãos } & \multicolumn{2}{|c|}{$\begin{array}{c}\text { Incremento de FDN na } \\
\text { ração, \% }\end{array}$} & \multirow{2}{*}{ Média } & \multicolumn{3}{|c|}{ Análise de Variância } \\
\hline & 0 & 8 & & $\mathrm{EPM}^{1}$ & $\mathrm{CV}^{2}, \%$ & $\mathrm{P}=\mathrm{F}$ \\
\hline Duodeno & 17,10 & 17,85 & 17,47 & 6,44 & 36,90 & 0,3692 \\
\hline Jejuno/Íleo & 21,94 & 21,52 & 21,73 & 7,45 & 34,29 & 0,6630 \\
\hline Ceco & 14,41 & 14,60 & 14,50 & 5,27 & 36,39 & 0,7822 \\
\hline Colo & 19,82 & 18,47 & 19,15 & 6,22 & 32,52 & 0,0957 \\
\hline
\end{tabular}

'Erro padrão da média, ${ }^{2}$ Coeficiente de variação. Não houve diferença significativa pelo teste de Tukey. $\mathrm{N}=12$ animais/tratamento

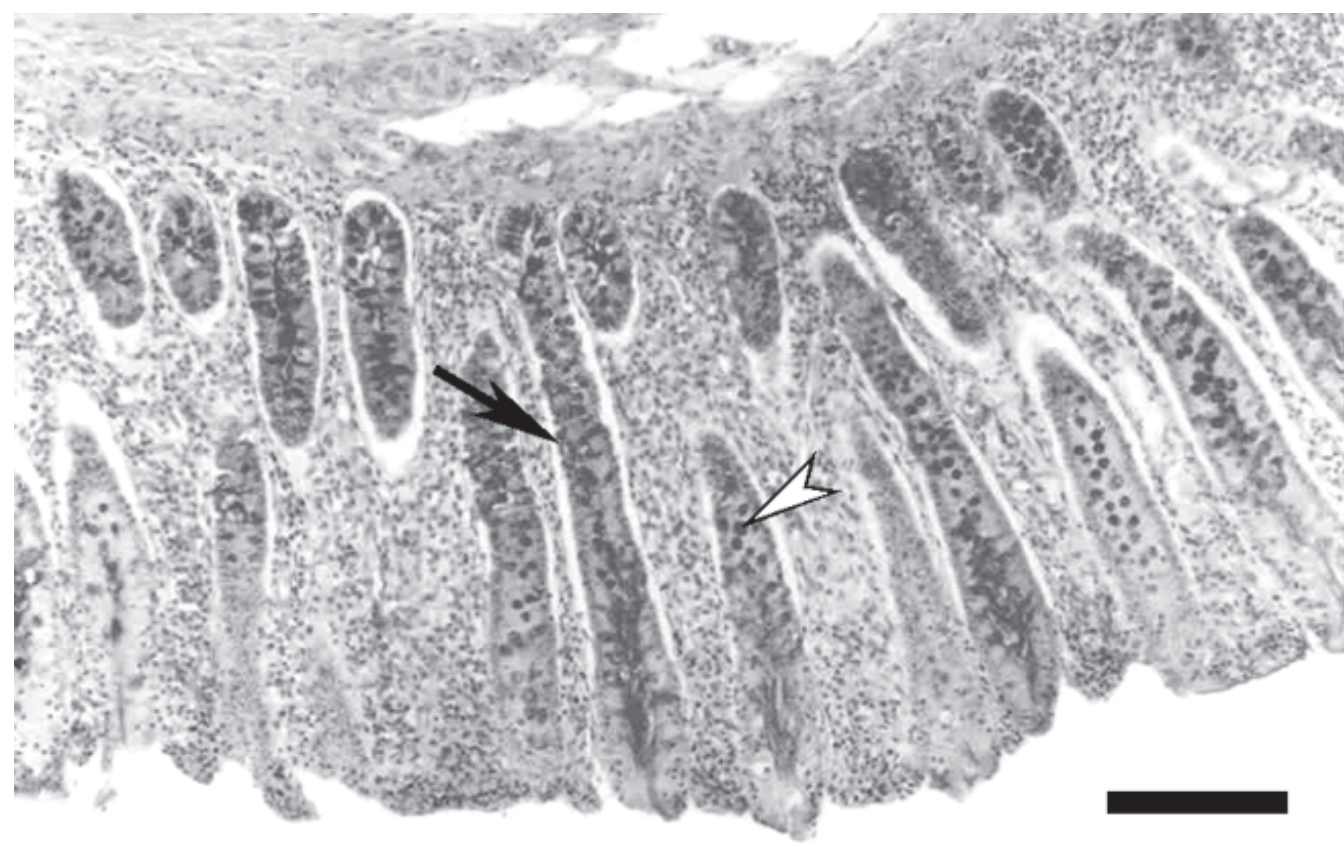

Figura 2 - Microfotografia da mucosa do ceco de um animal recebendo 8\% de FDN adicionado à dieta. Notar o aumento de freqüência das glândulas intestinais (seta em preto) e das células caliciformes (ponta de seta em branco). Barra $=100 \mu \mathrm{m}$; Coloração Hematoxilina-PAS

fibra em detergente neutro na ração de suínos nas fases de creche de crescimento-terminação promoveu alterações histológicas na mucosa intestinal, particularmente na fase de creche. Estas alterações traduziram-se no aumento da área glandular, estímulo à produção e liberação de muco pela mucosa intestinal, indicando que suínos jovens apresentam possivelmente maiores respostas adaptativas à presença de fibra na dieta do que suínos na fase de crescimento-terminação ou então que, suínos nesta fase, já estariam mais tolerantes à presença de quantidade moderada de fibra na ração.

\section{Agradecimentos}

Os autores agradecem o auxílio financeiro concedido pela Fundação de Amparo à Pesquisa do Estado de São Paulo (FAPESP). 


\title{
Effects of increasing neutral detergent fiber in swine diets on the morphology of digestive and non-digestive organs
}

\begin{abstract}
The aim of this work was to evaluate the effects of including $0 \%$ or $8 \%$ of neutral detergent fiber in swine rations on the histological aspects of gastrointestinal segments of starting and growing-finishing pigs. It was employed cross-bred animals fed isoproteic and isoenergetic ad libitum rations in a completely randomized experimental design. At the end of each experiment, animals were slaughtered, eviscerated and pieces from digestive organs prepared for histological studies. For starter animals, the fibrous diet increased significantly the cecal glandular volumetric proportion; reduced the goblet cell volumetric proportion on jejunum epithelium; and enhanced the intensity of mucous production by duodenal and colonic mucous cells. By the end of finishing period, the pigs fed fibrous diets showed increased glandular surface area on cecal epithelium but slight reduction of mucosal cell surface area on the colon. These data suggest an epithelium adaptation, possibly a protective mechanism against the abrasive action promoted by the continuous feeding of dietary fiber to swine, particularly in the starting period.
\end{abstract}

Key-words: Intestinal epitelium.

\section{Referências}

1 GOMES, J. D. F. Efeitos do incremento da fibra em detergente neutro, sobre parâmetros de desempenho, de digestibilidade dos componentes dietéticos e da morfologia intestinal de marrãs. 1996. 110f. Tese (Doutorado) - Faculdade de Medicina Veterinária e Zootecnia, Universidade Estadual Paulista, Botucatu.

2 PENZ JÚNIOR, A. M. Alimentação à vontade para porcas em gestação. In: SEMINÁRIO NACIONAL DE SUINOCULTURA, 2., 2001, Foz do Iguaçu. Anais... p. 29-52.

3 STAHLY, T. S.; CROMWELL, G. L. Responses to dietary additions of fiber (alfalfa meal) in growing pigs housed in a cold, warm or hot thermal environment. Journal of Animal Science, v. 63, p. 1870-6, 1986

4 BROUNS, F.; EDWARDS, S. A.; ENGLISH, P. R. Effect of dietary fibre and feeding system on activity and behaviour of housed gilts. Applied Animal Behaviour Science, v. 39, p. 215-223, 1994

5 RAMONET, Y.; MEUNIER-SALAÜN; M. C.; DOURMAD, J. Y. High-fiber diets in pregnant sows: digestive utilization and effects on the behavior of the animals. Journal of Animal Science, v. 77, p. 591-599, 1999

6 ROBERT, S.; MATTE, J. J.; FARMER, C.; GIRARD, C. L.; MARTINEAU, G. P. High-fiber diets for sows: effects on stereotypes and adjuntive drinking. Applied Animal Behaviour Science, v. 37, p. 297-309, 1993.

7 BECKER, B. G. Bem-estar dos suínos. In: SIMPÓSIO NACIONAL DE SUINOCULTURA, 2., Brasil, 2001,. Foz do Iguaçu Anais... p. 95-102.

8 GOMES, J. D. F.; SOBRAL, P. J. A.; FAGUNDES, A. C. A.; FUKUSHIMA, R. S.; LIMA, C. G.; SOUZA, L. W. O.; UTIYAMA, C. E.; OETTING, L. L. FDN na alimentação de suínos em pré-reprodução e reprodução: efeitos sobre desempenho produtivo, reprodutivo e características de carcaça. In: CONGRESSO LATINO AMERICANO DE SUINOCULTURA, 1., 2002, FOZ do Iguaçu, Anais... p. 251-252.

9 LUNA, A. M. Bienestar de los cerdos: las normas europeas y una propuesta de bienestar razonable. In: CONGRESSO LATINO AMERICANO DE SUINOCULTURA, 1., 2002, Foz do Iguaçu. Anais... p. 22-43.

10 BERTO, D. A.; KRONKA, R. N.; SANTOS, H. S. L.; THOMAZ, M. C.; CURTARELLI, S. M. Efeitos do tipo de ração inicial sobre a morfologia intestinal e digestibilidade dos nutrientes em leitões. Revista da Sociedade Brasileira de Zootecnia, v. 25, p. 973-986, 1996.

11 TUCCI, F. M. Estudo da adição de virginiamicina e ?-glucanase exógena às racões de leitões e seus efeitos sobre o desempenho e morfologia intestinal. 1999. 
76f. Dissertação (Mestrado) - Faculdade de Medicina Veterinária e Zootecnia, Universidade de São Paulo, Pirassununga.

12 TUCCl, F. M. Efeitos da adição de agentes tróficos na dieta de leitões desmamados sobre a renovação celular da mucosa intestinal, enzimas digestivas desempenho. 2003. 84f. Tese (Doutorado) - Faculdade de Ciências Agrárias e Veterinárias, Universidade Estadual Paulista, Jaboticabal.

13 MOORE, R. J. et al. Growth nutrient utilization and intestinal morphology of pigs fed high fiber diets. Journal of Animal Science, v. 66, p. 1570-1579, 1988.

14 VAREL, V. H.; POND, W. G.; YEN, J. T. Influence of dietary fiber on performance and large intestinal microflora of growing swine. Swine Research Progress Report, n. 1, p. 51-52, 1983.

15 NATIONAL RESEARCH COUNCIL - NRC. Nutrient requirements of pigs. 10. ed. Washington: National Academy of Sciences, 1998. 189 p.

16 GOERING, H. K.; VAN SOEST, P. J. Forage fiber analysis: apparatus, reagents, procedures and some applications. Washington: Agricultural Research Service, 1970. 76 p.

17 ASSOCIATION OF OFFICIAL ANALYTICAL CHEMISTS - AOAC. Official methods of analysis. Washington: Association of Analytical Chemistry, 1980. 1015 p.

18 WEIBEL, E. R. Steriological methods. In: Practical methods for biological morphometry. Sulffolk: Academic Press, 1989.v. 1, 380p.

19 LILLE, R. D.; FULLMER, H. Histopathologic technic and practical histochemistry. 4 ed. New York: McGraw-Hill, 1976. 942 p.

20 SAS INSTITUTE. SAS user's guide: statistics. Cary, NC: SAS Institute, 1992.

21 SCHNEEMAN, B. O. Fiber, inulin and oligofrutose: similarities and differences. The Journal of Nutrition, v. 129 , p. 1424 S-7S, 1999

22 VAREL, V. H.; POND, W. G. Cellulolytic bacteria from gestating swine fed various levels of dietary fiber. Swine Research Progress Report, n. 2, p. 54-55, 1986.

23 BRUNSGAARD, G. Effects of cereal type and feed particle size on morphological characteristics, epithelial cell proliferation, and lectin binding patterns in the large intestine of pigs. Journal of Animal Science, v. 76, p. 2787-2798, 1998 .

24 VON ENGEELHARDT, W.; RÖNAU, K.;
RECHKEMMER, G.; SAKATA, T. Absorption of shortchain fatty acid and their role in the hindgut of monogastric animals. Animal Feed Science and Technology, v. 23, p. 43-53, 1989.

25 SAKATA, T. Chemical and physical trophic effects of dietary fibre on the intestine of monogastric animals. Pig News Information, v. 12, p. 165, 1991. Abstracts

26 CLEMENS, E. T. Dietary fiber and colonic morphology. In: CAREY, D. P.; NORTON, S. A.; BOLSER, S. M.(ed.). Recent advances in canine and feline nutritional research: Proceedings of the1996. I ams International Nutrition Symposium. Wilmington: Orange Frazer, 1996. p. 25-32.

27 CERA, K. R.; MAHAN, D. C.; CROSS, R. F. Effect of age, weaning and postweaning diet on small intestine growth and jejunal morphology in young swine. Journal of Animal Science, v. 66, p. 574-584, 1998.

28 NABUURS, M. J. A. Morphological, structural and functional changes of the small intestine of pigs at weaning. Pig News Information, v. 16, p. 93N-97N 1995.

29 JIN, L. et al. Effects of dietary fiber on intestina growth, cell proliferation, and morphology in growing pigs. Journal of Animal Science, v. 72, p. 2270-2278, 1994. 